\title{
Determinants and Spatial Distribution of Multidimensional Poverty in Cameroon
}

\author{
Paul Ningaye ${ }^{1} \&$ Aloysius Mom Njong ${ }^{2}$ \\ ${ }^{1}$ Faculty of Economics and Management, University of Dschang, Cameroon. \\ ${ }^{2}$ Faculty of Economics and Management, University of Bamenda, Cameroon. \\ Correspondence: Paul Ningaye, Faculty of Economics and Management, University of Dschang, Cameroon.
}

Received: June 10, 2014

doi:10.11114/ijsss.v3i1.619
Accepted: June 30, $2014 \quad$ Available online: December 24, 2014

URL: http://dx.doi.org/10.11114/ijsss.v3i1.619

\begin{abstract}
The aim of this study is to target poverty following a multidimensional approach. The Multiple Correspondence Analysis, the P $\alpha$ class of poverty measures and the logistic regression permitted us to construct a Composite Welfare Index, to draw up multidimensional poverty profiles and to identify its determinants. The results show that, with regard to the spatial distribution, Cameroon's regions can be divided into three: an area of extreme multi-poverty, an area of non-multi-poverty, and an area in between. With regard to socio-economic characteristics, the residential area variable was found to be an absolute determinant. Monetary poverty is obviously considerable in this distribution, and so are existence poverty, infrastructural poverty and human poverty. Policies aimed at fighting poverty must target the areas of extreme multi-poverty and rural areas on the basis of shortages of capabilities in all these dimensions.
\end{abstract}

Keywords: Multidimensional poverty, poverty indicators, composite poverty index

\section{Introduction}

Conceptually, the multidimensional poverty approach is opposed to unidimensional approaches, which view welfare according to revenue or expenditure. Underlying the multidimensional approach is the argument that all non-monetary attributes of welfare have no markets, and when these do exist they are imperfect (Bourguignon and Chakravarty, 2002). For these reasons, there is unanimity about the multidimensional conception of poverty (Sen 1979, 1985; World Bank, 2000; Thorbecke, 2005; African Development Bank, 2006) and the governments of most African countries among which Cameroon, through the Poverty Reduction Strategy Papers (PRSPs), have adhered to this idea.

However, the inclusion of the multidimensional approach in anti-poverty policies does not follow this conceptual advance because we must first identify the poor, locate them and describe their characteristics. The aim of this study is to contribute to targeting poverty within a multidimensional framework. Its specific objectives are: a) to determine the different angles of multidimensional poverty; b) to draw a profile of multidimensional poverty; c) to identify the determinants of multi-poverty; and d) to compare multidimensional profile to monetary profile.

Several methodological alternatives for quantifying a Composite Welfare Index (CWI) from which multi-poverty can be studied are presented in the literature review. The Human Development Index (UNDP, 1977) and the deprivation index (Townsend, 1979; Alkire and Foster, 2008) are criticised because the elementary indicators could not have the same importance in the welfare perception. The limit of the parametric approach proposed by Maasoumi (1999) came up from the fact that if the information contained in the base does not reflect the entropy function, the weights are biased. In the fuzzy set approach, the rules of calculation of the weights are external to the base thus decided by the analyst.

All these deficiencies can be overcome if we apply the inertia approach. This is a non-parametric approach according to which all the weights are endogenous to the data set from which they are determined by statistical rules. This is why, the Multiple Correspondence Analysis (MCA) first enables us to construct a CWI which aggregates the values of basic indicators for each household. The dynamic scatter classification further allows us to construct three thresholds that have served to draw multidimensional profiles of poverty. Finally, a regression analysis is used to identify the determinants of multi-poverty.

The rest of the paper is organized as follows: Section 1 presents the literature review. Section 2 the theoretical framework. Section 3 the methodology. Section 4 presents and discusses the results and Section 5 concludes the paper 
by making policy recommendations.

\section{Literature Review}

From the basic indicators of welfare we can construct composite indices of multi-poverty that are decomposable into subgroups or according to specific attributes (Bourguignon and Chakravarty, 2002; Chakravarty, Mukherjee and Ranade, 1998). However, in line with our objectives, the CWI should rather be constructed to combine an individual's responses into a numerical value. There have been many suggestions to this effect that varied as a function of the weight attributed to each indicator. According to some authors, these weights should be equal while the CWI is an average of the responses to the different variables (UNDP, 1997). Following the same logic, we can determine the threshold for each basic indicator and then add them together. The number of indicators under the threshold will give the deprivation index for an individual (Townsend, 1979; Alkire and Foster, 2008). The works of the National Institute of Statistics (NIS, 2002) and that of Tachi (2003) are in light with this orientation in the Cameroonian context. Considering the same weights to the indicators is questionable because they should not have the same importance in the welfare perception and then in poverty.

The approaches suggesting that the weights allocated to the indicators must vary as a function of their contribution to welfare are the most common. In the so-called entropy approach, also called the parametric approach, the CWI is based on the optimization of an entropy function (Maasoumi, 1999). The weights applied to the aggregating functions are criticized in the sense that, if the entropy function does not reflect the information contained in the data set, they are biased (Asselin, 2009). In the fuzzy set approach, the weighting coefficients are in an inverse relationship with the deprivation frequency in such a way that the fewer households are deprived of a possession, the greater the weight allocated to the indicator measuring the ownership of the previous possession (Cerioli and Zani, 1990; Cheli and Lemmi, 1995; Gianni and Vijay, 2008). Njong and Baye (2010) applied this approach in Cameroon and arrived at the conclusion that the incidence of multi-poverty rose from $42.08 \%$ in 1996 to $50.39 \%$ 2001. Unfortunately, the weights in this approach are intuitive and exogenous to the data set. In addition, a threshold must be fixed for the poverty indicators in order to calculate the deprivation indicator, which could be risky.

In order to overcome all these limits in the present research we have worked out the inertia method.

\section{Theoretical Framework}

According to the theory of capabilities, poverty is a concept and, hence, unobservable. It can only be captured through measurement variables or indicators and is then, called latent variables (Krishnakumar and Ballon, 2008). In such a situation, the inertia approach is most appropriate for two reasons: (i) it is non-parametric and we do not need any functional form; (ii) all the weights applied to the indicators in the aggregating process are endogenous to the data set from which they are determined by statistical rules. The approach actually rests on a set of statistical methods that seek to summarise the information contained in a data set by small number of composite variables or factors, or even latent variables. Some specific methods used in the inertia approach include Principal Component Analysis, Factor Analysis, Generalized Canonical Analysis and the Multiple Factor Analysis (MFA) if the variables are quantitative. These analyses use the Euclidian distance in their algorithm of seeking latent variables. Where the variables are ordinal or qualitative, the MCA should be used where the chi-square distance serves in the estimations (Asselin, 2009).

The works of Ningaye (2011) and of Ningaye et al. (2012) which used Structural Equation Modelling to study some specific aspects of multi-poverty applied the inertia approach in Cameroon. However, the researchers' aim was not to draw up a profile of multi-dimensional poverty, as it is the case in the present study. Another study is that by Foko et al. (2007) which, while following objectives that are close to ours, obtained weightings on indicators by using the MFA. This methodology is criticized because the MFA algorithm has been conceived primarily for quantitative variables and can be adapted to qualitative variables only at the price of intermediate computations (Diday et al., 1982, Foko et al. 2007). The present study uses the MCA which is directly applicable to qualitative variables.

\section{Research Methodology}

\subsection{Source of Data and Variables of the Study}

The data analyzed is taken from a large-scale national survey called ECAM II that was carried out by the National Institute of Statistics in Cameroon between September and December 2001 (NIS, 2002). The final sample answers that is analyzable is made up of 10,992 households.

From ECAM II, we have to extract the basic indicators of poverty. To this effect we have at our disposal several theoretical proposals for the identification of poverty dimensions as well as how they work (Razafindrakoto and Roubauf, 2005; Hulme and McKay, 2008; Sindzingre, 2008; Polomar, 2008). From the clarifications of these different authors, thirty-seven variables were extracted as indicators of multidimensional poverty in the context of this study. Not all these thirty-seven basic indicators are taken into account in the construction of the CWI for two reasons: firstly, the 
six indicators of subjective poverty are excluded because recent researches have established profiles of subjective poverty that are very different from objective profiles (Pradhan and Ravallion, 2000; Ravallion and Lokshin, 2000). This made Thorbecke (2005) to state that subjective indicators are suited to small entities such as villages and communities. Secondly, the question that sought to provide information about whether the head of the household had been ill for the previous two weeks do not seem relevant for our study, as the answer could depend on seasons without necessarily reflecting the real state of health. At the end of this analysis, the remaining thirty variables are prepared for a multiple correspondence analysis (MCA). In this light, the quantitative variables that are very limited in number, such as distances in relation to basic infrastructure, are first of all re-coded as ordinal in order for all the variables to be analyzed in the same way.

\subsection{Construction of Composite Welfare Index}

In the present study, the interest of the MCA is two-fold: first to identify multi-poverty dimensions as well as their measurement variables (Benzécri, 1980); second to construct a CWI for each household. The rationality of the choice of variables to be included in the computation of the CWI is the property of the First Axis Ordinal Consistency (FAOC). According to this property, the modalities of the indicators describing a poverty situation must have increasing scores on the first factor axis which is the poverty axis (Asselin, 2009). Seven variables, which do not satisfy the FAOC property, are excluded from the analyses. The MCA of the twenty-three variables with fifty-six modalities (see Table 1) brings about an improvement in the egenvalues $(\lambda 1=0.30$ and $\lambda 2=0.10)$ as well as their explanatory powers of $20.66 \%$ and $7.03 \%$ respectively. The modalities with a positive score (on axis 1) positively contribute to welfare while those with negative scores reduce welfare. All the results of multi-poverty quantification in the inertia approach are based on these scores.

Asselin (2009) took inspiration from the MCA results and, in particular the coordinates of the modalities on the first axis and proposed a CWI. In its functional form, $\mathrm{Ci}$ (the CWI of household i) is defined by the author as:

$$
C_{i}=\frac{\sum_{k=1}^{K} \sum_{j_{k}=1}^{j_{k}} \boldsymbol{W}_{j_{k}}^{k} \boldsymbol{I}_{i, j_{k}}^{k}}{K}
$$

where $\mathrm{K}$ is the number of indicators in ordinal form; $\mathrm{Jk}$ is the number of modalities of the indicator $\mathrm{K} ; W_{j_{k}}^{k}$ is the weighting coefficient corresponding to the standardized score on the first factor axis of the modality $\mathrm{J}_{\mathrm{k}} \operatorname{score} / \sqrt{\lambda_{1}}$ that are reported in Table 1. $\lambda_{1}$ is the egenvalue of the first factor, $I_{i, j k}^{k}$ is the binary variable taking the value 1 if the household has the modality $\mathrm{p}$ and 0 otherwise.

Table 1. Results of the Multiple Correspondence Analysis

\begin{tabular}{llll}
\hline $\mathrm{N}^{\circ}$ & Variables Description & Modalities Description & $1^{\text {st }}$ axis score* \\
\hline 1 & Living standard & Monetary poor & -0.75 \\
& & inter-monetary & -0.26 \\
& & Monetary non-poor & 0.45 \\
2 & Source of lighting in the house & Paraffin oil lighting & -0.89 \\
& & Electricity lighting & 0.58 \\
3 & Source of energy used for cooking & Sawmill waste/collected firewood & -0.82 \\
& & Bought firewood/charcoal & 0.29 \\
& & Electricity/gas & 1.29 \\
4 & Type of toilet & Non-fitted latrines & -0.69 \\
& & Fitted latrines & 0.60 \\
5 & Materials used to build the walls & Mud/stubble & -0.47 \\
& & concrete/perpend/stones & 0.78 \\
6 & Materials used to build the roof & mat/thatch & -1.37 \\
& & Iron sheet/tile & 0.21 \\
7 & Materials used as flooring & soil & -0.94 \\
& & cement/tiles & 0.61 \\
8 & Possession of fixed telephone & No fixed telephone & -0.05 \\
& & Possession of fixed tel. & 1.59 \\
9 & Possession of mobile telephone & No mobile telephone & -0.15 \\
& & Possession of mobile tel. & 1.42 \\
10 & Possession of a radio & No radio & -0.63 \\
\hline
\end{tabular}




\begin{tabular}{|c|c|c|c|}
\hline & & Possession of radio & 0.39 \\
\hline \multirow[t]{2}{*}{11} & Possession of a gas stove & No gas stove & -0.23 \\
\hline & & Possession of gas stove & 1.14 \\
\hline \multirow[t]{2}{*}{12} & Possession of paraffin-oil stove & No paraffin oil stove & -0.29 \\
\hline & & Possession of paraffin oil stove & 0.61 \\
\hline \multirow[t]{2}{*}{13} & Possession of a TV set & No TV set & -0.37 \\
\hline & & Possession of TV set & 1.09 \\
\hline \multirow[t]{2}{*}{14} & Possession of an iron & No iron & -0.52 \\
\hline & & Possession of iron & 0.68 \\
\hline \multirow[t]{3}{*}{15} & Source of drinking water supply & Wells/rivers & -0.75 \\
\hline & & Water seller/public fountain & 0.45 \\
\hline & & tap/borehole & 0.62 \\
\hline \multirow[t]{2}{*}{16} & Type of health centre & Traditional healers & -0.56 \\
\hline & & Modern health centre & 0.12 \\
\hline \multirow[t]{4}{*}{17} & Level of education & No formal education & -0.77 \\
\hline & & Primary education & -0.23 \\
\hline & & Secondary education & 0.50 \\
\hline & & Tertiary education & 1.30 \\
\hline \multirow[t]{2}{*}{18} & Number of children expelled from school & Children expelled at least once & -0.08 \\
\hline & & Children never expelled & 0.29 \\
\hline \multirow[t]{3}{*}{19} & Change in level of education since 1996 & Level diminished & -0.19 \\
\hline & & Level did not change & 0.16 \\
\hline & & Level improved & 0.25 \\
\hline \multirow[t]{3}{*}{20} & Distance from the nearest primary school & Distance $>=6 \mathrm{~km}$ & -1.54 \\
\hline & & $2<=$ distance $<=5 \mathrm{~km}$ & -0.35 \\
\hline & & Distance $<=1 \mathrm{~km}$ & 0.19 \\
\hline \multirow[t]{3}{*}{21} & Distance from an integrated health centre & Distance $>=6 \mathrm{~km}$ & -1.19 \\
\hline & & $2<=$ distance $<=5 \mathrm{~km}$ & -0.11 \\
\hline & & Distance $<=1 \mathrm{~km}$ & 0.39 \\
\hline \multirow[t]{3}{*}{22} & Distance from the nearest market & Distance $>=6 \mathrm{~km}$ & -1.17 \\
\hline & & $2<=$ distance $<=5 \mathrm{~km}$ & -0.19 \\
\hline & & Distance $<=1 \mathrm{~km}$ & 0.32 \\
\hline \multirow[t]{3}{*}{23} & Distance from the nearest asphalted road & distance $>=6 \mathrm{~km}$ & -0.93 \\
\hline & & $2<=$ distance $<=5 \mathrm{~km}$ & -0.32 \\
\hline & & distance $<=1 \mathrm{~km}$ & 0.57 \\
\hline
\end{tabular}

Source: Authors' estimations

$*=$ first-axis factor scores

After the computations, the CWI is a quantitative variable with a minimum of -14.98 and a maximum of 15.20 . As most of the computations of a welfare indicator are designed according to the assumption that it is a positive variable, we did a translation of the CWI by adding 15 to its values.

The final CWI thus has a minimum of 0.02 and a maximum of 30.20. Its means is 15.06 and its standard deviation 6.65.

From this distribution of the CWI, we have used automatic classification method highly recommended by Luzzi, Flückiger and Weber (2008) to identify poverty typologies in a multi-dimensional approach. Considering the size of the sample (10,992 households) an algorithm of the "Dynamic Clouds" type was applied (Diday, 1971). By considering the partition into two classes cluster 1 has 5,949 individuals. The maximum value of the CWI for this cluster is 30.20 and its minimum value is 14.57 . As far as cluster 2 is concerned, it has a number of 5,040 individuals. The maximum value of the CWI for this cluster is 14.64 while its minimum value is 0.02 .

From these figures, and in order to reduce arbitrariness in (i) the distinction between the poor and the non-poor and (ii) in the comparison of the monetary poverty profile with that of multidimensional poverty, we set up three multi-dimensional thresholds. The first is a higher threshold (htd) obtained from the results of the partitioning into two classes and approximated by the [maximum value of the CWI in the class of the poor] * [weight of the class of the poor] + [minimum value of the CWI in the class of the non-poor] * [weight of the class of the non poor] (Asselin and Tuan, 2009). The application is $[14.57 *(5949 / 10989)]+[14.64 *(5040 / 10989)]=14.6$. The second is an intermediate threshold (ith) designed in a way to have the same poverty rate like the one obtained through the monetary approach 
$(40,2 \%)$. Its value is 9.9 . The third is a lower threshold (ltd) designed to reflect the extreme multi-poverty. It is derived from a three-class classification and its value is 8.28.

\subsection{Logistical Regression}

The logistic regression is the statistical technique that have found most appropriate to identifying the determinants of multi-poverty. Indeed, some of these determinants are measured by qualitative or ordinal variables and others by quantitative variables. They are symbolized by $\mathrm{x} 1$ - - - xp. The multi-poverty to be explained (y) can be coded binary by assigning the value 1 to a poor person and 0 to a non-poor one. Consider $p_{x}=\operatorname{pr}(y=1 / x)$ the probability of $y=1$, that is, to be poor for any value of $\mathrm{x}$. From px we define a logit px quantity by:

$$
\log \text { it } p_{x}=\log \frac{p_{x}}{1-p_{x}}
$$

It has been demonstrated that there exists a linear relationship between the logit px and the explanatory variables x1 - $\mathrm{xp}$ to the extent that we can write:

$$
\log t p_{x}=\frac{p_{x}}{1-p_{x}}=\beta_{0}+\beta_{1}+---+\beta_{p}
$$

The estimation of Equation (3) by the likelihood method gives the $\beta$ coefficients from which we can deduce the odds ratio, that is, the ratio of likelihood between the modalities of each on the $\mathrm{x}$ variables. This is, for example, the ratio of the likelihood of a person from the rural area to be poor compared to a person from the urban area. This means that the "rural versus urban residential area" is assigned the code 1 for a rural person and 0 for an urban person, since a higher poverty rate is observed in the rural area than in the urban area.

If the odds ratio is greater than 1 , the variable $\mathrm{x}$ points to an aggravation of poverty and additional tests will indicate whether the likelihood differences are significant. If $\mathrm{x}$ is a quantitative variable, it is considered as such in the modelling. It is the same if $\mathrm{x}$ is binary. However, if on the other hand $\mathrm{x}$ is ordinal having $\mathrm{g}+1$ as modalities, it is introduced by $\mathrm{g}$

\begin{tabular}{|c|c|c|c|}
\hline $\mathrm{x} 1$ & $\mathrm{z} 1$ & $\mathrm{z} 2$ & $\mathrm{zg}$ \\
\hline 0 & 0 & 0 & 0 \\
\hline 1 & 1 & 0 & 0 \\
\hline 2 & 0 & 1 & 0 \\
\hline • & . & . & . \\
\hline . & . & . & . \\
\hline 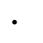 & 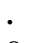 & 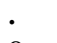 & . \\
\hline $\mathrm{g}$ & 0 & 0 & $\mathrm{~g}$ \\
\hline
\end{tabular}
indicator variables obtained by:

For $\mathrm{x}$, the 0 modality is called basic modality and will serve as the reference for interpretation. For each Z, 1 indicates that it is the modality concerned. An observation of the profiles shows that all the explanatory variables are transformed into ordinal variables, and then into indicator variables.

\section{Results of Study}

The results are based on the angles and profiles of multi-poverty and on the identification of its determinants.

\subsection{Different Angles of Multidimensional Poverty}

The special nature of the MCA lies in the fact that its interpretation of dimensions is based on grouping together the modalities of the analyzed variables (Lautsch and Plichta, 2003). In this light, the modalities of the variables are represented in the plane formed by these two factors as a function of their respective coordinates on each of these factors. This leads us to distinguish five dimensions:

The monetary poverty dimension. Based on the ECAM II survey, The NIS (2002) have assigned codes to three categories of living standards: the households whose adult-equivalent expenses are less than CFAF 232,547 are considered poor; those whose expenses are between CFAF 232,547 and CFAF 345,535 are considered intermediate, while those whose expenses are higher than CFAF 345,535 are considered non-poor. Table 1 illustrates an important dimension in the study of poverty as it contrasts, the "monetary poor" with the "monetary non-poor" and the "intermediate".

The existence poverty dimension. This is an objective, non-monetary indicator that looks at poverty from the material conditions of housing. The goal is to bring into the study of the phenomenon a dimension of stocks that is durable in time, as opposed to monetary variables that are subject to variations linked to the current economic situation. Fourteen 
indicators are taken into account: a) source of lighting in the house, b) source of energy used for cooking, c) type of toilet, d) materials used to build the walls, e) materials used as roofing, f) materials used as flooring, $g$ ) possession of fixed telephone, $h$ ) possession of mobile telephone, i) possession of a radio, $\mathrm{j}$ ) possession of a gas stove, $\mathrm{k}$ ) possession of paraffin-oil stove, l) possession of a TV set, $\mathrm{m}$ ) possession of an iron, and $\mathrm{n}$ ) source of drinking water supply. These indicators are appropriate to measure this dimension according to Table1.

The human poverty dimension. This approach brings the concept of poverty to the fore by highlighting the shortage of capabilities. Like in the case of the preceding dimension, the indicators bear on a stock that has not been affected by unforeseen factors linked to the current economic situation. They thus capture a structural form of poverty. Two of the five variables characterizing "shortages" in terms of human capital and which are measured in ECAM II satisfy the FAOC property: a) the level of education of the head of the household, and b) the type of health centre the household goes to for medical care.

The infrastructural poverty dimension. There are four items for which there is a satisfactory statistical solution to capture this latent variable. Here, Table 1 contrasts households that are located more than $6 \mathrm{~km}$ from the nearest primary school, health centre, the market, and an asphalted road with those that are located less than $1 \mathrm{~km}$ from these facilities. Between the two extreme distances are households that are located between 2 and $5 \mathrm{~km}$ from the same facilities.

The financial poverty dimension. This reflects subjective monetary poverty which concerns households that can have a sufficient level of consumption but are still vulnerable due to the precarious conditions they live in. There are two items for which signs of weak financial capability were measured: the one which refers to the number of times a child has been expelled from school for non-payment of school fees, and the evolution of living standards for the last five years.

These statistical results show that poverty is a multidimensional phenomenon covering five facets of which the monetary dimension is just one.

\subsection{Profiles of Multidimensional Poverty}

The measure used in the present study is the P $\alpha$ class of measures of poverty developed by Foster, Greer and Thorbecke (1984). There are two possible profiles of multi-poverty. The first one results from the spatial decomposition of the composite index while the second one results from its decomposition according to household socio-economic characteristics. The variables that led to the building of the CWI are no longer considered. Monetary profile is linked to each other.

Table 2, which is a summary of the decomposition of multi-poverty on the spatial level, reveals a relatively stable classification of regions. It enables a division of the country into three areas: the first is an area of extreme multi-poverty where the incidence of the composite index is always higher than the national value irrespective of the threshold considered. The area in question is composed of the Far-North, the North, the North-West, the East and the Centre. The second is an intermediate area where the incidence of multi-poverty is lower than the national value and is composed of the regions of the South, the South-West, the West, Adamawa, and the Littoral. The third is an area of non-poverty composed of the two big cities namely Douala and Yaounde.

In order to understand the reasons for this spatial discrepancy, we have examined the indicators that were taken into account in the building of the CWI. The regions of the Far-North and the South are chosen as representative of each of the spaces of extreme poverty and intermediate poverty. It turns out that the monetary element is significant, but not as much of a determinant as the other types of shortages of capabilities related to existence poverty and human poverty. Indeed $25.4 \%$ of the population in the extreme poverty category, against $38.5 \%$ in the intermediate poverty category, is classified as poor on the monetary dimension. However, considerable disparities are observed in two dimensions: the first disparity has to do with existence poverty according to which $42.4 \%$ of the extreme poverty population have fitted latrines, compared to $60.2 \%$ for the intermediate category. Likewise, $74.5 \%$ of the extreme poverty population have got houses whose floors were made of earth while $63.9 \%$ of the intermediate poverty population have got houses whose floors are made of cement or tiles. Moreover, up to $41.3 \%$ of the extreme poverty population have got houses whose roofs are built of mats, compared to only $2.6 \%$ for the others. The second dimension where great disparities are observed is that of human poverty where $64.6 \%$ of the extreme poor population did not have formal education compared to $7.10 \%$ for the other side. Also, when we take health $23.79 \%$ of the extreme poor population seeks medical care from traditional healers compared to $9.3 \%$ of the population living in less multidimensional poverty. 


\begin{tabular}{|c|c|c|c|c|c|c|c|c|}
\hline \multirow[t]{3}{*}{ Region } & \multicolumn{6}{|c|}{ Composite index } & \multicolumn{2}{|c|}{ Monetary index } \\
\hline & \multicolumn{2}{|l|}{ htd(14.6) } & \multicolumn{2}{|l|}{ itd (9.9) } & \multicolumn{2}{|l|}{ Itd (8.28) } & & \\
\hline & $\mathrm{p}_{0 j^{*}}$ & $\mathrm{C}_{0 \mathrm{j}^{* * *}}$ & $P_{0 j}$ & $\mathrm{c}_{0 \mathrm{j}}$ & $\mathrm{p}_{0 \mathrm{j}}$ & $\mathrm{c}_{0 \mathrm{j}}$ & $\mathrm{p}_{0 \mathrm{j}}$ & $\mathrm{c}_{0 \mathrm{j}}$ \\
\hline Total population & 59.0 & 100 & 40.2 & 100 & 31.2 & 100 & 40.2 & 100 \\
\hline Yaoundé & $3.6(12) ㅇ$ & 0.5 & $0.2 \quad(12)$ & 0.0 & $0.0(12)$ & 0.0 & $18.3(12)$ & 3.9 \\
\hline Douala & $5.9 \quad(11)$ & 0.9 & $0.2 \quad(11)$ & 0.0 & $0.0(11)$ & 0.0 & $18.5(11)$ & 4.4 \\
\hline Adamaoua & $70 \quad(6)$ & 5.3 & $37.5 \quad(7)$ & 4.1 & $28.4(7)$ & 4 & $45.8(5)$ & 5 \\
\hline Centre & $76.3 \quad$ (3) & 10 & $45.6 \quad(5)$ & 8.9 & $33.4(5)$ & 8.4 & $60.3(1)$ & 11.7 \\
\hline East & $75 \quad(4)$ & 6.1 & $54.4 \quad(3)$ & 6.5 & $43.4(3)$ & 6.6 & $47.0(4)$ & 5.6 \\
\hline Far- North & $90.1 \quad(1)$ & 2.7 & $73.1 \quad$ (1) & 3.2 & $60.8(2)$ & 34.5 & $41.7(6)$ & 18.4 \\
\hline Littoral & $44.3(10)$ & 3.6 & $18.3(10)$ & 2.2 & $10.1(10)$ & 1.5 & $44.1(7)$ & 5.3 \\
\hline North & $79.6(2)$ & 9.7 & $67.3 \quad(2)$ & 12.1 & $63.2(1)$ & 14.7 & $49.0(3)$ & 8.8 \\
\hline North-West & $71.8(5)$ & 14 & $49.3 \quad(4)$ & 14.3 & $35.1(9)$ & 12.9 & $52.7(2)$ & 15.1 \\
\hline West & $64 \quad(7)$ & 13 & $42.5 \quad(6)$ & 12.7 & $29.5(6)$ & 11.4 & $38.0(9)$ & 11.4 \\
\hline South & $55.1(8)$ & 3.2 & $28.9 \quad(8)$ & 2.5 & $18.4(8)$ & 2 & $38.6(8)$ & 3.3 \\
\hline South-West] & 47.7 (9) & 6 & 22.2 & 4.1 & $14.6(9)$ & 3.5 & $35.0(10)$ & 6.5 \\
\hline
\end{tabular}

${ }^{*} \mathrm{p} 0 \mathrm{j}$ is the FGT index for $\alpha=0$. It gives the incidence of poverty in region $\mathrm{j}$ as a percentage

$* * \mathrm{c} 0 \mathrm{j}$ gives the contribution of region $\mathrm{j}$ to total poverty as a percentage

우 The figures in brackets indicate the decreasing classification of the poverty incidence according to the threshold considered.

Source: Authors' estimations

This spatial decomposition enables us precisely to identify the spaces where there is a concentration of poor households. For a more effective implementation of anti-poverty policies, the characteristics which are specific to households or individuals and which contribute to multi-poverty must be highlighted. Table 3 summarizes the results.

Apart from the size of the household, the hierarchy of incidences of multi-poverty has been retained with regard to the different thresholds.

The analysis based on the environment variable shows that multidimensional poverty is primarily a phenomenon of the rural area, irrespective of the threshold. At the lower threshold, it contributes $98.8 \%$ of the poverty at the national level, with an incidence of 54.1 , compared to $2 \%$ contributed by the semi-urban area and $0 \%$ by the urban. Generally, the rural area faces numerous shortages of capabilities compared to the urban area. On the monetary poverty dimension, $68.12 \%$ of urban dwellers are classified like non-poor, against only $32.71 \%$ of rural dwellers. Similar results are observed on the dimensions of existence poverty, human poverty, equipment poverty and infrastructural poverty.

Table 3. Decomposition of Poverty According to Household Socio-Economic Characteristics

\begin{tabular}{|c|c|c|c|c|c|c|c|c|c|}
\hline & \multirow[t]{3}{*}{ Modality } & \multicolumn{6}{|c|}{ Composite index } & \multicolumn{2}{|c|}{ Monetary index } \\
\hline & & \multicolumn{2}{|c|}{$\operatorname{htd}(14.6)$} & \multicolumn{2}{|c|}{ itd $(9.9)$} & \multicolumn{2}{|c|}{ Itd (8.28) } & \multirow[b]{2}{*}{$\mathrm{p}_{0 \mathrm{j}}$} & \multirow[b]{2}{*}{$\mathrm{c}_{0 \mathrm{j}}$} \\
\hline & & $\mathrm{p}_{0 j^{*}}$ & $\mathrm{c}_{0 \mathrm{j} * *}$ & $\mathrm{p}_{0 \mathrm{j}}$ & $\mathrm{c}_{0 \mathrm{j}}$ & $\mathrm{p}_{0 \mathrm{j}}$ & $\mathrm{c}_{0 \mathrm{j}}$ & & \\
\hline \multirow{4}{*}{ 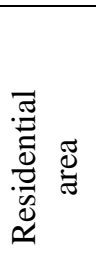 } & Total population & 59.0 & 100 & 40.2 & 100 & 31.2 & 100 & 40.2 & 100 \\
\hline & Urban & 11.5 & 6.7 & 1.3 & 1.1 & 0.00 & 0.00 & 22.1 & 19.1 \\
\hline & Semi-urban & 34.5 & 4.7 & 7.3 & 1.4 & 3 & 0.00 & 24.9 & 5 \\
\hline & Rural & 91.6 & 88.4 & 68.5 & 97.3 & 54.1 & 98.9 & 53.4 & 75.8 \\
\hline \multirow{4}{*}{ 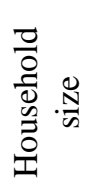 } & 1 person & 57.5 & 0.2 & 38.1 & 2.5 & 27.3 & 2.3 & 11.8 & 0.07 \\
\hline & 2 people & 61.3 & 5.6 & 42.9 & 5.7 & 30.7 & 5.3 & 17.2 & 2.3 \\
\hline & 3 to 4 people & 59.8 & 18 & 41.7 & 18.4 & 33.5 & 19.0 & 29.3 & 12.9 \\
\hline & 5 to 7 people & 61.6 & 35.3 & 41.2 & 34.8 & 30.9 & 33.6 & 41.7 & 35.2 \\
\hline
\end{tabular}




\begin{tabular}{|c|c|c|c|c|c|c|c|c|c|}
\hline & 8 people and more & 56.3 & 38.4 & 38.3 & 38.4 & 30.7 & 39.6 & 48.6 & 48.7 \\
\hline \multirow{4}{*}{ 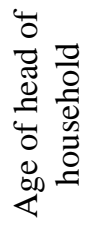 } & Less than 30 years of age & 58.3 & 15 & 41.2 & 15.6 & 30.9 & 15 & 31.05 & 11.7 \\
\hline & 30 to 40 years & 51.1 & 30.3 & 33.3 & 29.1 & 25.5 & 28. & 35.7 & 31.2 \\
\hline & 45 to 59 years & 58.9 & 30.4 & 39.5 & 30 & 32.5 & 31.8 & 45.2 & 34.3 \\
\hline & 60 years and + & 74.5 & 24.1 & 52.8 & 25.1 & 39.7 & 24.3 & 47.5 & 22.6 \\
\hline \multirow{2}{*}{ 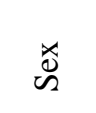 } & Male & 59.5 & 82.3 & 40.6 & 82.6 & 31.6 & 82.8 & 40.5 & 82.3 \\
\hline & Female & 56.8 & 17.6 & 37.9 & 17.3 & 29.5 & 17.4 & 38.7 & 17.6 \\
\hline \multirow{6}{*}{ 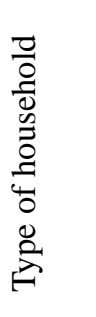 } & Impersonal & 56.9 & 2.5 & 37.8 & 2.5 & 27.1 & 2.3 & 11.6 & 0.00 \\
\hline & Single parent, strictly & 64 & 6.5 & 43.8 & 6.5 & 33.9 & 6.5 & 41.7 & 0.006 \\
\hline & Single parent, extended & 50 & 8.9 & 30.6 & 8 & 23.4 & 7.9 & 42.3 & 11.1 \\
\hline & Nuclear family, strictly & 64.8 & 28.4 & 46.34 & 29.9 & 36.6 & 30.4 & 42.4 & 27.3 \\
\hline & Nuclear family, extended & 44.6 & 20.5 & 28.2 & 19.1 & 21 & 18.3 & 37.9 & 25.6 \\
\hline & Other type, extended & 70.5 & 32.9 & 49.2 & 33.8 & 38.9 & 34.3 & 41.9 & 28.7 \\
\hline \multirow{6}{*}{$\stackrel{\mathscr{E}}{\stackrel{\Xi}{\tilde{E}}}$} & Single & 37.3 & 4.6 & 19.5 & 3.5 & 14.3 & 3.3 & 23.7 & 4.3 \\
\hline & Married, monogamous & 57.1 & 48.9 & 39.4 & 49.6 & 30.8 & 49.9 & 39.3 & 49.5 \\
\hline & Married, polygamous & 69.2 & 29.1 & 48.2 & 29.8 & 38.4 & 30.5 & 46.7 & 28.8 \\
\hline & Widower/widowed & 67.6 & 10.9 & 45.5 & 10.8 & 35.8 & 10.9 & 43.4 & 10 \\
\hline & Divorced/separated & 59.3 & 2.8 & 41.9 & 3 & 28.5 & 2.6 & 34.3 & 2.4 \\
\hline & Cohabitation & 42.6 & 3.4 & 26.1 & 3.1 & 16.6 & 2.5 & 37.4 & 4.5 \\
\hline \multirow{6}{*}{ 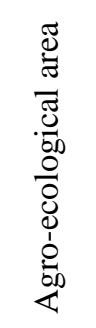 } & Yaoundé & 3.6 & 0.0 & 0.2 & 0.0 & 0.0 & 0.0 & 18.3 & 3.9 \\
\hline & Douala & 5.9 & 0.0 & 0.2 & 0.0 & 0.0 & 0.0 & 18.5 & 0.4 \\
\hline & Other towns & 19.1 & 5.2 & 2.6 & 0.1 & 0.0 & 0.0 & 26.2 & 10.6 \\
\hline & Rural area, forest & 78.1 & 19.1 & 49.5 & 17.8 & 37 & 17.1 & 55.3 & 19.9 \\
\hline & Rural area, high plateau & 78.6 & 34.9 & 50.6 & 33 & 35.0 & 29.4 & 50.7 & 33.1 \\
\hline & Rural area, savannah & 94.4 & 39.1 & 78.5 & 47.8 & 67.7 & 53.1 & 45.6 & 27.8 \\
\hline \multirow{5}{*}{ 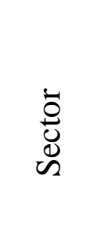 } & Public administration & 12.9 & 0.1 & 4.6 & 0.0 & 2.7 & 00 & 13.0 & 2.6 \\
\hline & State-owned company & 35.5 & 0.1 & 6.7 & 0.0 & 1.9 & 0.0 & 36.4 & 2.2 \\
\hline & Formal private enterprise & 18.9 & 0.3 & 4.2 & 1.2 & 2.1 & 0.0 & 16.8 & 4.8 \\
\hline & Informal farming enterp. & 91.4 & 74.8 & 70 & 84 & 56.0 & 86.8 & 54.5 & 65.6 \\
\hline & Informal non-farming ent. & 37.6 & 11.5 & 16.9 & 7.6 & 11.4 & 6.6 & 33.1 & 14.9 \\
\hline
\end{tabular}

Source: Authors' estimations

The multi-poverty incidence varies from $38.1 \%$ for households with one person to $38.3 \%$ for households with eight people and more. Even if it reaches $42.9 \%$ in households with two persons, the multi-poverty incidence varies little according to the size of the household. This low variation could be due to the fact that the survey concentrated on households where several individuals share the same living conditions.

The three thresholds confirm that multi-poverty is greater in the group of those aged less than 30 years. It then decreases for the next age-group and increases for the other age- groups. The statistics show that at less than 30 years of age, people have a sufficient income to be classified like non-poor. Thus $66.2 \%$ of people in this age-group are classified like non-poor, compared to $54.9 \%$ in the 30 to 40 year-old group. They have not yet acquired certain durable goods items like a fixed telephone or a gas stove: only $0.8 \%$ of them possessed the former and $20.8 \%$ the latter, compared to $2.5 \%$ and $21.6 \%$ respectively for those in the higher age group. In addition, they also have not yet got a comfortable house. The rural aspect also seems to be a contributing factor: $30.8 \%$ of people in that age group are rural, compared to $28.8 \%$ for the next age group. Moreover, the rural area is yet characterized by a shortage of basic infrastructure.

With regard to the characteristic of sex, multi-poverty is found to be slightly more severe in households whose head is a male than those whose head is a female. However, this should not overshadow the three main areas where male capabilities are higher than female ones. The first is the area of human poverty where $37.60 \%$ of female heads of 
households are without formal education, compared to only $23.4 \%$ for their male counterparts. Likewise, only $3.6 \%$ of the female heads of households have a tertiary education, against $9.30 \%$ of males. The second area concerns certain aspects of the "equipment poverty" dimension: $55.46 \%$ of the households headed by females have not got a radio, against $33.73 \%$ of those headed by males; $63.41 \%$ of the former did not have an iron, against $55.87 \%$ of the latter; and $79.45 \%$ of them do not have a TV set, compared to $74.19 \%$ of those headed by males. The third area concerns all the indicators of financial poverty: $50.2 \%$ of female heads of households, against $33.03 \%$ of their male counterparts, reported that their income have decreased and that they have had a child expelled from school for non-payment of school fees. This means that despite their more favourable position, the female-headed households experience greater difficulty in maintaining their living standards.

Whatever the threshold considered, the impersonal household type experiences a multipoverty incidence that is higher than that experienced by the "extended single parent" type. Yet the people in that type have the lowest proportion of monetary poverty and are the most highly educated. Age seems to be a relevant variable here because $49.6 \%$ of the people in the impersonal household type are below 30 years of age. This explains why in spite of their monetary resources they have not yet acquired a certain number of durable goods that would have contributed to higher scores in their classification.

Differences in the status of households reveal three typologies of multi-poverty. The first one contrasts polygamous households with monogamous ones: multi-poverty is found to be more severe in the case of the former than the latter. The most significant shortages are observed in the human dimension poverty where $23.31 \%$ of heads of monogamous households do not have formal education, compared to $39.47 \%$ of polygamous households. $52.7 \%$ of monogamous households reported that their living standard dropped, while 33.6\% of them said that their child have been expelled from school; the figures for polygamous households are $57.8 \%$ and $38.1 \%$, respectively. A similar trend is observed in relation to indicators of existence poverty.

The second typology contrasts widowed people with divorced ones: $57.82 \%$ of those widowed are without formal education while only $38.24 \%$ of the divorcees are. Similarly, only $11.71 \%$ of the widowed have had secondary school education while $24.71 \%$ of the divorcees have. The difference in the monetary poverty dimension is equally remarkable as only $48.57 \%$ of the widowed people are non-poor while $59.71 \%$ of the divorced ones are. In the other dimensions, the differences are not significant. Overall, multi-poverty is more marked among the widowed than among the divorcees.

The third typology of poverty with regard to matrimonial status contrasts single people with couples in cohabitation. These two groups are very similar in the sense that they do not usually have children, which enables them to allocate the bulk of their resources to improve their living conditions. The poverty incidences for these two groups were found to be very similar and lower than those for the other groups.

The agro-ecological area variable which involves the types of cash crops farmed confirms that multi-poverty is more of a rural than an urban phenomenon. Nevertheless, it also revealed that rural areas encounter different problems with incidences of $49.5 \%, 50.6 \%$ and $78.5 \%$ for the forest rural, high-plateau rural and the savannah rural respectively. If we consider the higher threshold, the figures show that the savannah rural area, which is the poorest at a multidimensional level, have shortages compared to the other rural areas on two dimensions. First, there is the existence poverty dimension where $74.0 \%$ of households use paraffin oil for lighting, $92 \%$ have houses with walls built of mud, 55.5\% have houses with roofs built of mats, $74.0 \%$ have houses with flooring made of earth, and $93.8 \%$ do not have a TV set. The figures for the same variables are $56.7 \%, 70.7 \%, 5.5 \%, 52.7 \%$ and $80.4 \%$ for the high-plateau rural area, and $52.0 \%$, $80 \%, 12.9 \%, 56.2 \%$ and $84.6 \%$ for the forest rural area. Second, there is the human poverty dimension and, in particular, the level of formal education, where $64.3 \%$ of the households in the savannah rural area are without formal education compared to $24.7 \%$ for those in the high-plateau rural and $18.4 \%$ for the forest rural area. The forest rural area suffers from a shortage of road infrastructure where $63.6 \%$ of its population reported living more than $6 \mathrm{~km}$ from the nearest tarred road. The figures are $51.4 \%$ for the high-plateau rural and $57.5 \%$ for the savannah rural areas.

The most important incidences of multi-poverty are observed in the sectors of informal farming enterprises and formal farming enterprises. These sectors generate small monetary revenues $(41.9 \%$ of the employees of the informal farming sector and $20.1 \%$ of those in the non-informal farming sector were classified as poor), employ a workforce that is little educated $(44.7 \%$ of the employees in the informal sector and $24.6 \%$ of those in the formal sector were classified as being without formal education) and are, mostly, to be found in rural areas.

\subsection{Determinants of Multidimensional}

The identification of the determinants of multidimensional poverty is based on an explanatory method in order to see whether the variations revealed by observing the profiles of poverty are statistically significant. The logistic regression used in the present study was initially conceived to deal with a binary explained variable and one or several explanatory 
variables that are also binary. But nowadays it has been generalized to cases where the explanatory variables are qualitative, ordinal, or quantitative, as long as the conditions explained in the section Logistical Regression are met. Three models have been tried following different thresholds of multi-poverty. The model corresponding to the higher threshold is the preferred one with its pseudo- $\mathrm{R}$ of 0.5390 , compared to 0.5367 for the intermediate threshold and 0.4692 for the lower one. The estimations appear in Table 4 .

Table 4. Determinants of Multi-Poverty

\begin{tabular}{lllllll}
\hline No. & Description & Odds ratio & Std. error & $\mathrm{z}$ & $\mathrm{P}>\mathrm{z}$ & $\mathrm{X} 0=$ basis \\
\hline 1 & 2 persons & .2279358 & .2267252 & -1.49 & 0.137 & 1 person \\
2 & 3 to 4 persons & .2463366 & .2460908 & -1.40 & 0.161 & \\
3 & 5 to 7 persons & .2793475 & .2792249 & -1.28 & 0.202 & \\
4 & 8 persons and more & .202785 & .2031627 & -1.59 & 0.111 & \\
5 & Below 30 years of age & .8919417 & .0845225 & -1.21 & 0.228 & 30 to 40 years \\
6 & 49 to 59 years & 1.226548 & .107481 & 2.33 & $0.020^{*}$ & \\
7 & 60 years and more & 1.663045 & .190159 & 4.45 & $0.000^{* *}$ & \\
8 & Semi-urban & 5.583298 & .975467 & 9.84 & $0.000^{* *}$ & Urban \\
9 & rural & 76.83344 & 14.01717 & 23.80 & $0.000^{* *}$ & \\
10 & Male & 1.002981 & .1258508 & 0.02 & 0.981 & Female \\
11 & Impersonal & .3894492 & .3886887 & -0.94 & 0.345 & \\
12 & Strictly single parent & 1.695225 & .3146146 & 2.84 & $0.004^{*}$ & Extended nuclear \\
13 & Extended single parent & 1.184096 & .2010107 & 1.00 & 0.320 & \\
14 & Strictly nuclear family & 1.834535 & .1967547 & 5.66 & $0.000^{* *}$ & \\
15 & Other extended family & 1.635165 & .208063 & 3.86 & $0.000^{* *}$ & \\
16 & Married, monogamous & 1.152396 & .1528233 & 1.07 & 0.285 & Single \\
17 & Married, polygamous & 1.132551 & .164223 & 0.86 & 0.391 & \\
18 & Widower/widowed & 1.669936 & .2595383 & 3.30 & $0.001^{* *}$ & \\
19 & Divorced/separated & 1.544926 & .2754303 & 2.44 & 0.015 & \\
20 & Cohabitation & .9407672 & .1641845 & -0.35 & 0.726 & \\
21 & Yaoundé & .5086908 & .1286155 & -2.67 & $0.008^{*}$ & Douala \\
22 & Other towns & 3.074032 & .4841229 & 7.13 & $0.000^{* *}$ & \\
23 & High plateau rural & 6.5889173 & .0642013 & -4.86 & $0.000^{* *}$ & \\
24 & Savannah rural & 8.562836 & .3150146 & 7.66 & $0.000^{* *}$ & \\
25 & Public administration & .4107405 & .0633263 & -5.77 & $0.000^{* *}$ & Formal public enterprise $*$ \\
26 & Public enterprise $\dagger$ & 1.010613 & .2159796 & 0.05 & 0.961 & \\
27 & Informal farming enterp.\# & 7.92853 & .8718349 & 18.83 & $0.000^{* * *}$ & \\
28 & Informal non-farming enterprise + & 2.852594 & .2949631 & 10.14 & $0.000^{* *}$ & \\
\hline
\end{tabular}

$*$ significant at the $5 \%$ level, $* *$ significant at the $1 \%$ level, $\ddagger$ formal private enterprises, $\dagger$ public enterprises, \# informal farming enterprises, 우 informal non-farming enterprises

Source: Authors' estimations

The odds ratios measure the ratio of chance when moving from the reference modality to another modality within the same variable. If it is higher than 1 , this movement leads to an increase in the risk of falling into multi-poverty. If in addition, the probability $(\mathrm{p}>\mathrm{z})$ is $<1 \%$ or $5 \%$, then the risk is significant. If during the process of analysis two indicator variables are correlated, one of them will be automatically eliminated. This has been the case for the forest rural area, which in Table 3 already had a multi-poverty profile very similar to that of the high-plateau rural area. The results show that the size of the household is not a potential determinant, because moving from a one-member household to households with as many members as eight do not increase the risk of falling into multipoverty.

On the other hand, the "residential area" variable is found to be the only determinant threshold because moving from the basic modality to the other modalities significantly increases the risk of falling into multi-poverty in all cases. For example, people living in the semi-urban area are five times more likely to fall into poverty than those living in the urban area. The same risk is 76 times higher for those living in the rural area.

Halfway between the two extreme cases are relative determinants. With the variables at this intermediate level, moving from the basic modality does not significantly increase the risk of increasing poverty for all the other modalities.

Thus, the poverty for the less than 30 year age is not found to be significantly higher than that of 30 to 40 year age section, which is considered as the basis. By contrast, it is exactly the opposite for all the other age groups. For the "type of household" variable, the poverty for the "impersonal" and "extended single parent" modalities was not 
significantly different from that of the "extended nuclear family" modality taken as the basis. However, it was for the other modalities, namely "strictly single parent", "strictly nuclear family", and "other extended family". The matrimonial status is also a relative determinant in the sense that the poverty of single people, of married monogamous people, of married polygamous people and of those living in cohabitation are not found to be significantly different, as we would have expected from their profiles. Nonetheless, moving from the state of being single to that of being widower/widowed or divorced/separated significantly increases the risk of seeing multipoverty rise. The agro-ecological zone is also found to be a relative determinant in the sense that the multipoverty profiles for Douala and Yaoundé are very similar. In the other cases, the risks of falling into multipoverty become higher when we move from these cities into rural areas. They become even higher when we move to the savannah rural area. The last relative determinant is the sector of activity: moving from formal private enterprises to public administration or public enterprises does not increase the risk of poverty. However, this risk becomes real when moving to informal non-farming enterprises or informal farming enterprises.

\subsection{Multidimensional Poverty and Monetary Poverty}

As monetary poverty and multidimensional poverty use different methodological and conceptual approaches, it is not possible to directly compare their respective incidences. In the following paragraphs we will make comparisons based on how the two approaches classify their poverty profiles.

On the spatial distribution dimension, and considering the intermediate threshold (which have enabled us to get the same poverty incidence like the monetary approach), information about which appears in Table 2, the two approaches agree in the fact that the big cities of Douala and Yaoundé experience less poverty. However, despite this similarity, the multidimensional approach inverts the classification based on the monetary approach. For example, the two poorest regions on the monetary level turns out to be the Centre and the North-West while on the multidimensional level the two are found to be the Far-North and the North. On the whole, five regions see their classification tumble (which means more poverty) by moving from the monetary to the multidimensional poverty. The five are the East, the Far-North, the North, the West and the South-West. The situation is reversed for the other five regions, namely Adamaoua, Centre, Littoral, North-West and South. In order to understand what underlies these conflicting results, we have analyzed the indicators taken into account in the construction of the CWI for the extreme cases, that is those of the Far-North and Centre regions.

The two approaches produce similar results with regard to their classifications of the modalities of two variables relate to household socio-economic characteristics. The first variable is the sex of the head of the household. In all cases, poverty is slightly more severe in the households headed by males. However, the explanatory approach shows that the difference is not significant with regard to multi-poverty. The second variable is the residential area. However, in relation to this the CWI lays emphasis on rural poverty in the sense that the rural area contributes for $97.3 \%$ to the national poverty when multi-poverty is considered and for $75.8 \%$ when we consider the monetary poverty.

Apart from the two characteristics, the two approaches produce different results with the other variables. Here are three illustrative cases: the first suggests that the incidence of monetary poverty increases with the size of the household. However, both the observation of profiles and the approach based on determinants confirms that those variations were not significant according to the multidimensional perspective. The second case shows that the incidence of monetary poverty increases according to age group. Multidimensional poverty is found to be higher for those aged less than 30 years. It then reduces in the next age group but rose again in the other age group. In the third case monetary poverty identifies the impersonal type of family size as the least poor whereas multi-poverty identifies the extended nuclear family type as the least poor.

After a closer analysis, we realized that the two approaches diverged on such a big number of variables because the multidimensional approach included, in its study of poverty, first monetary indicators, followed by the welfare indicators that cannot be easily acquired through people's incomes. This is the case with infrastructure of all kinds. It further included the welfare indicators which can only be acquired at the cost of an effort to save or the acquisition of which is conditioned by the existence of a given type of infrastructure. This is the case of TV or radio sets which require the pre-existence of electrical infrastructure. It is also the case of the level of education and the type of health centre variables which hinge on the prior existence of schools and modern health centres. The multidimensional approach thus seems appropriate when the country is called upon to improve the living conditions of its people. The policies of direct increase of income are thus no longer enough.

\section{Conclusion and Recommendations}

Below is the gist of the findings of the present study. On the spatial level, three areas have been identified. The first comprises the Far-North, the North, Adamaoua, the East, the North-West and the Centre. This first area is called one of extreme multipoverty because the incidence of poverty is always higher there than elsewhere in the country irrespective 
of the threshold taken into account. The second area is composed of the South, South-West, Littoral and West regions. It is a space of intermediate poverty. The third is a space of non-poverty composed of the two biggest towns, Douala and Yaoundé. Monetary poverty is, admittedly, unequally distributed, but it is not as essential in the spatial distribution of multi-poverty as are existence poverty, infrastructural poverty and human poverty. Anti-poverty policies must be implemented in areas of extreme multi-poverty on the basis of shortages of capabilities on those dimensions.

At the level of socio-economic characteristics, the residential area variable is found to be an absolute determinant of multi-poverty in that moving from the urban to the semi-urban area increases by five times the risk of multi-poverty level. This risk became 76 times higher if we move from the urban to the rural area. In fact, compared with the urban area, the rural area suffers from a lack of capabilities on the dimensions of existence poverty, human poverty, equipment poverty and infrastructural poverty. Otherwise, the variables of activity sector and agro-ecological area are the relative determinants in the sense that the changing of the basic level to another level does not increase the risk of multi-poverty. Nevertheless, the study found that employees in the informal farming enterprises and the inhabitants of the savannah rural areas were the poorest.

Classifications of the profiles of multidimensional and monetary profiles are very different for the majority of variables. This was because the main contribution of the multidimensional approach to the study of poverty included several dimensions of living conditions. This has permitted us to better take into account the people's welfare in the recommendations.

\section{Acknowledgements}

Our heartfelt gratitude goes to the African Economic Research Consortium (AERC), for providing the grant to carry out this research and to the staff of AERC Secretariat for facilitating the study. We are also grateful for the very useful and insightful comments of members of the AERC network, which were invaluable in improving this paper.

\section{References}

African Development Bank. (2006). African Development Report. African Development Bank.

Alkire, S., \& Foster, J. (2008). Counting and multidimensional poverty measurement. OPHI Working Paper Series, 7 , Oxford Poverty and Human Development Initiative, Oxford.

Asselin, L. M. (2009). Theory. In Asselin L. M., Analysis of multidimensional Poverty: theory and Cases Studies, Springer, London New york, 3-74.

Asselin, L. M., \& Tuan, V. (2009). Dynamic Poverty Analysis in Vietnam 1993-2002. Multidimensional versus Money-Metric Analysis. In Asselin L. M., Analysis of multidimensional Poverty: theory and Cases Studies, Springer, London New york, 76-112.

Benzécri, J. (1980). L'analyse des données, Analyse des correspondances, exposé élémentaire. Paris: Dunod.

Bourguignon, F., \& Chakravarty, S. R. (2002). The measurement of multidimensional poverty. Journal of Economic Inequality, 1, 25-49.

Cerioli, A., \& Zani, S. (1990). A fuzzy Approach to the measurement of Poverty. In Dagum et Zenga (eds), Income and wealth distribution, Inequality and poverty, Springer, Berlin

Chakravarty, S. R., Mukherjee, D., \& Ranade, R. (1998). On the family of subgroup and factor decomposable measures of multidimensional poverty. Research on Economic Inequality, 8, 75-94.

Cheli, B., \& Lemmi, A. (1995). Totally Fuzzy and relative Approach to the multidimensional Analysis of poverty. Economics notes, 24(1), 12-25

Diday, E. (1971). Une nouvelle méthode en classification automatique et reconnaissance de formes. La méthode des nuées dynamiques. Revue de statistique appliquée, 19(2), 19-33.

Diday, E., Lemaire, J., Pouget, J., \& Testu, F. (1982). Éléments d'analyse de données. Paris: Dunod.

Foko, T., Ndem, F., \& Tchakote, R. (2007). Pauvreté et inégalités des conditions de vie au Cameroun: une approche micro-multidimensionnelle. Cahier de Recherche PMMA, 2007-02.

Foster, J. E. Greer, J., \& Thorbecke, E. (1984). A class of Decomposable Poverty Measures. Econometrica, 52, $761-776$.

Gianni, B., \& Vijay, V. (2008). Fuzzy measures of incidence of relative poverty and deprivation: a multidimensional perspective. Statistical Methods and Applications, 17, 225-250.

Hulme, D., \& Mckay, A. (2008). Identifying and measuring chronic poverty: Beyond monetary measures, in Kakwani N. and Silber J (Eds.) Quantative Approaches to Multidimensional Poverty Measurement, Basingstoke: Palgrave Macmillan, 56-70. 
Krishnakumar, J., \& Ballon, P. (2008). Estimating Basic Capabilities: a Structural Equation Model Applied to Bolivia. Word Development, 36(6), 992-1010.

Lautsch, E., \& Plichta, M. M. (2003). Configural Frequency Analysis (CFA), Multiple Correspondence Analysis (MCA) and Latent Class Analysis (LCA): An empirical comparison. Psychology Science, 45, 298-323.

Luzzi, G. F., Flückiger Y., \& Weber, S. (2008). Multidimensional poverty and cluster analysis: an illustration with Switzerland, in Kakwani N. and Silber J (Eds.) Quantative Approaches to Multidimensional Poverty Measurement, Basingstoke: Palgrave Macmillan, 135-152.

Maasoumi, E. (1999). Multidimensional approaches to welfare analysis. In J. Silber ed., Handbook of Income Inequality Measurement. Boston: Kluwer Academic Publishers.

National Institute of Statistics (NIS). (2002). Household Living Conditions and Poverty Profile in Cameroon in 2001: Main report and the second Cameroon household survey. NIS, Yaounde, Cameroon.

Ningaye, P. (2011). Ethno-cultural diversity and multidimensional poverty differential in Cameroon. International Journal of Development Issues, 10(2), 123-140.

Ningaye, P., Tiomela, Y. A., \& Takoutio, F. V. (2012). Multi-Poverty in Cameroon: A Structural Equation Modeling Approach. Social Indicators Research. http://dx.doi.org/10.1007/s 11205-012-0087-8.

Njong, M. A., \& Baye, M. F. (2010). Asset Growth, Asset Distribution and Changes in Multidimensional Poverty in Cameroon. African Journal of Economic Policy, 17(1), 85-104.

Polomar, J. L. (2008). The subjective dimension of poverty: a psychological perspective, in Kakwani N. and Silber J (Eds.) Quantative Approaches to Multidimensional Poverty Measurement, Basingstoke: Palgrave Macmillan, 12-28.

Pradhan, M., \& Ravallion, M. (2000). Measuring poverty using qualitative perceptions of consumption adequacy. The Review of Economics and Statistics, 82(3), 462-71.

Ravallion, M., \& Lokshin, M. (2000). Identifying welfare effects from subjective questions. Economica, 68, 335-357.

Razafindrakoto, M., \& Roubaud, F. (2005). Les multiples facettes de la pauvreté dans un pays en développement: le cas de la capitale malgache. Economie et Statistiques, 131-155.

Sen, A. K. (1979). Personal utilities and public judgment: Or what's wrong with welfare economics?. Economic Journal, $89,537-558$.

Sen, A. K. (1985). Commodities and Capabilities. Amsterdam: North-Holland.

Sindzingre, A. (2008). The multidimensionality of poverty: An institutionalist perspective, in Kakwani N. and Silber J (Eds.) Quantative Approaches to Multidimensional Poverty Measurement, Basingstoke: Palgrave Macmillan, 123-157.

Tachi, S. (2003). Analyse de la pauvreté au Cameroun: une approche multidimensionnellen Revue Africaine de Sciences Economiques et de Gestion, 2, 17-42.

Thorbecke, E. (2005). Multi-dimensional poverty: Conceptual and measurement issues. Paper presented at The Many Dimensions of Poverty Conference, 29-31 August, Brasilia, Brazil.

Townsend, P. (1979). Poverty in the United Kingdom - A Survey of Household Resources and Standards of Living. Harmondsworth: Penguin Books.

United Nations Development Programme (UNDP). (1997). Human Development Report. New York: Oxford University Press.

World Bank. (2000). World Development Report 2000/2001: Attacking Poverty. Oxford: Oxford University Press.

\section{(c) EY}

This work is licensed under a Creative Commons Attribution 3.0 License. 